\title{
Effects of Non-verbal Priming on Attachment-Style Activation
}

\author{
Suhyung Sim¹, Ji-eun Shin ${ }^{2}$ and Young Woo Sohn ${ }^{*}$ \\ ${ }^{1}$ Department of Psychology, Yonsei University, Seoul, South Korea, ${ }^{2}$ Department of Psychology, Chonnam National \\ University, Gwangju, South Korea
}

Using an affective priming procedure, two experiments examined the effects of nonverbal cues on activating attachment styles. In Study 1, the secure attachment group, which was primed non-verbally, showed higher levels of self-esteem, interpersonal competence, and positive affect than the insecure attachment group, which was also primed non-verbally. In contrast, no significant difference was found between the two attachment groups that were primed verbally. In Study 2, using a different priming method and adding a neutral group, similar interactions between priming modality (nonverbal or verbal cues) and attachment styles were found: the differences in self-esteem, interpersonal competence, and positive affect between the secure attachment group, neutral group, and insecure attachment group were greater when primed non-verbally than when primed verbally. Finally, the limitations of the research and recommendations for follow-up study are discussed.

\section{OPEN ACCESS}

Edited by:

Gianluca Castelnuovo, Università Cattolica del Sacro Cuore,

Italy

Reviewed by:

Barbara Colombo,

Champlain College, United States Mario Mikulincer,

Interdisciplinary Center Herzliya, Israel

*Correspondence:

Young Woo Sohn

ysohn@yonsei.ac.kr

Specialty section:

This article was submitted to

Clinical and Health Psychology, a section of the journal

Frontiers in Psychology

Received: 24 September 2018

Accepted: 12 March 2019

Published: 05 April 2019

Citation:

Sim S, Shin J and Sohn YW (2019) Effects of Non-verbal Priming on Attachment-Style Activation. Front. Psychol. 10:684. doi: 10.3389/fpsyg.2019.00684
Keywords: non-verbal cues, attachment style, affective priming, self-esteem, interpersonal competency, positive affect

\section{INTRODUCTION}

We communicate with others everyday using numerous verbal and non-verbal cues. Words are the most effective means for conveying messages that contain factual information (Chaiken and Eagly, 1976), but this may not be the case for emotional messages. In an attempt to offer consolation to distressed others, for example, a simple touch on the shoulder can be more effective than words (Ditzen et al., 2007). This is because emotion tends to be expressed and perceived through nonverbal channels, such as facial expression, voice tone, and posture, rather than verbally (Ekman and Friesen, 1975; Pally, 2008; App et al., 2011). Moreover, social communication-such as knowing what another is feeling and how one should respond to that emotional state-precedes the evolution of verbal abilities (Darwin, 1872/1998); thus it is not surprising that people communicate emotions through several non-verbal channels, including the face, body, and touch (Buck, 1984; App et al., 2011). In addition, unlike the verbal communication that occurs only through language, an emotion is a useful reaction that quickly transmits affective meaning in a natural way through the non-verbal channels noted above (Vrij, 2004; Weisbuch and Ambady, 2008). Based on the role non-verbal cues play in emotional communication, we aimed to examine how non-verbal cues relate to the fundamental basis of human emotional development: attachment (Thompson, 1994; Tucker and Anders, 1998; Riggio, 2006).

According to attachment theory, humans form attachment representations of self and others through interactions with primary caregivers (Ainsworth, 1969; Bowlby, 1969, 1973; Mahler et al., 1975; Fonagy, 2001). Here, "attachment representation" influences how people interpret their own behavior and feelings, as well as those of others (Beijersbergen et al., 2012). Attachment styles can generally be classified in two ways: secure attachment and insecure attachment (avoidant attachment and anxious attachment; Ainsworth et al., 1978/2015). Several studies have shown that securely attached individuals are likely to hold positive views of themselves and others, are more 
confident in their ability to deal with threats and challenges, and tend to employ more constructive and effective strategies for emotion regulation (e.g., problem solving, reappraisal, support seeking). Moreover, secure people can remain open to their emotions, express and communicate feelings freely and accurately to others, and experience them fully without distortion (Mikulincer and Shaver, 2018). On the other hand, insecurely attached people suppress their negative emotions and continue to rely on distorted views of self and others, which contributes to poor physical and mental health (Mikulincer and Shaver, 2016). Attachment anxiety triggers worries that others will not be available in times of need, and attachment avoidance gives rise to compulsive self-reliance and distrust of others' intentions. Both become maladaptive when applied to adult relationships in which support seeking and comfortable interdependence can help a person maintain a sense of well-being (Shaver and Mikulincer, 2002).

Attachment styles are largely based on attachment experiences in childhood and adolescence, and continue to exert an influence in adulthood in contexts that activate the attachment system, such as a romantic partner or close friends (Hazan and Zeifman, 1994; Ravitz et al., 2010). For instance, greater insecurity regarding parents and peers in adolescence predicts a more anxious romantic attachment style and greater use of emotionoriented strategies (e.g., worry about what action one should take) in adulthood (Pascuzzo et al., 2013). Indeed, activated mental representations of attachment figures (e.g., subliminal presentation of their names) result in heightened security and reduced hostility to out-group members, facilitate compassion and altruistic behavior toward needy others, and sustain creative problem solving (Mikulincer and Shaver, 2012).

In the formation of attachment representation, a focus on non-verbal behavior has played a substantial role (Mahler et al., 1975). Empirical evidence has established that the foundations of our mental representations are in place well before the acquisition of language (Wallin, 2007). Specifically, children develop an attachment style in the preverbal stage when they communicate with their primary caregiver through non-verbal cues. When an infant cries, the mother feeds it. When a baby is scared, the mother holds and reassures it. Such ordinary, repeated experiences confer a sense of secure attachment: "I'm a good enough person and people are trustworthy enough to be relied on" (Bowlby, 1969, 1973).

Nevertheless, few studies have investigated the non-verbal aspects of attachment style. Since non-verbal cues are important in the formation of an attachment style, they may still be important when the attachment representation is activated in adulthood. For instance, one can become calm and obtain a sense of security by simply visualizing the attachment figure's face (Mikulincer and Shaver, 2004; Mikulincer et al., 2005). Specifically, Jakubiak and Feeney (2016b) found that individuals who are reminded of affective experiences in which their attachment figure supported them using touch experienced less stress and were more willing to accept a challenge than those who were reminded of experiences in which their attachment figure supported them using words. This implies that there are two channels, non-verbal and verbal, through which an attachment style can be activated, and that the influence of each channel may vary. Jakubiak and Feeney's results show that the non-verbal channel is superior for conveying affective meaning. Wallin (2007) supports this argument by demonstrating that attachment representation cannot be linguistically retrieved, because our first relational experiences are mainly outside the domain of language. Therefore, we focus on the operating characteristics of the non-verbal channel in terms of attachment representation.

Further, previous studies that examined non-verbal behaviors and attachment style are limited, in that they do not consider the entire spectrum of non-verbal modalities (Scherer, 1995; Mikulincer and Shaver, 2007; Xiao et al., 2016). Non-verbal behaviors do not function independent of each other, but instead involve various behaviors that operate in multiple ways through different routes (Gunes et al., 2008). Accordingly, previous studies that focus only on one non-verbal modality, such as touch (Jakubiak and Feeney, 2016a), vocal rhythm (Beebe et al., 2000), or facial expression (Niedenthal et al., 2002) provide valuable information about the properties of a given non-verbal cue, but offer no comprehensive guidance about the effects of non-verbal behavior on an attachment style.

\section{The Present Study}

This study aimed to determine whether non-verbal behavior is an important factor in activating an attachment style. Specifically, in Study 1, we used an affective priming technique to examine whether a receptive non-verbal behavior and a rejecting nonverbal behavior of a significant other (e.g., primary caregiver) activate secure and insecure attachments, respectively. If one repeatedly experiences a significant other as being at one's side, responsive, and supportive, secure attachment is formed. Thus, we expected that a secure attachment style would be activated for a group that is reminded of a scene in which a significant other warmly gazes at them and supports them with non-verbal cues, and that an insecure attachment style would be activated for a group that is reminded of a scene in which a significant other discourages or rejects them with non-verbal cues. A verbal priming condition was used with the control group, which was instructed to recollect an experience of being accepted by or an experience of being rejected by the significant other. In addition, the priority was to recall what words had been said to them. This condition distinguishes this study and previous attachment studies, because we divided attachment-style activation routes into non-verbal and verbal priming and examined them under the same experimental conditions to compare variations according to different routes.

Specifically, we compared the magnitudes of the difference between secure and insecure attachments activated by nonverbal priming and the difference between secure and insecure attachments activated by verbal priming. For this purpose, we measured self-esteem, interpersonal competence, and positive affect through self-report questionnaires because the greater differences between secure and insecure attachment styles were revealed mainly in three areas: self-worth, confidence in others, and affective aspects (Feeney and Kirkpatrick, 1996; Fraley and Shaver, 1998; Collins and Feeney, 2000; Mikulincer et al., 2002). 
Taking these individually, first, a person with a secure attachment style has high self-esteem (Mickelson et al., 1997), confidence in one's own abilities, and the ability to use effective emotion regulation strategies in stressful situations (Canterberry and Gillath, 2013). Second, a person with a secure attachment style has confidence in others and expects their goodwill. Accordingly, the person does not become unnecessarily discouraged in interpersonal relationships and shows a high level of sociality (Hazan and Shaver, 1990; Mikulincer et al., 2001). Third, a person with a secure attachment style is more positive about life and experiences positive emotions more often (Selcuk et al., 2012). A psychological effect that can be immediately obtained from an attachment figure is affective stability, because one's interaction with an accessible and supportive attachment figure transfers that person's sense of security to oneself, thereby reducing one's anxiety and awakening positive emotions such as relief, satisfaction, and appreciation (Mikulincer and Shaver, 2007). For an infant to gain a sense of security, he or she must be approached by, see, and touch the attachment figure. In adulthood, however, other attachment strategies are available. For instance, a romantic partner or close friend can be an attachment figure, and one can become calm and obtain a sense of security by simply visualizing one's experiences with such a figure (Mikulincer and Shaver, 2004).

In Study 2, in line with Study 1, we used an affective priming technique to examine whether a non-verbal cue activates secure and insecure attachments. In this case, however, we aimed to improve the reliability and validity of the experiment through the use of a different attachment priming method, a larger sample size and the addition of a neutral group. Among these, the most critical difference between Studies 1 and 2 was the priming method. As described above for Study 1, through the scenario priming method, the focus was on activating attachment based on the non-verbal cue (i.e., eyes, posture, silence, etc.) or the verbal cue of the significant other. In contrast, in Study 2, we focused on priming attachment through the exclusive use of non-verbal or verbal cues. More specifically, in the case of the non-verbal priming condition, we used attachment-related photographs, which can be classified as non-verbal stimuli. In the case of the verbal priming condition, we used attachment-related words that can be regarded as verbal stimuli. Many studies have primed secure attachment by using such non-verbal stimuli as exposing participants to pictures that represent secure attachment (Zayas and Shoda, 2005; Mikulincer and Shaver, 2007; Bowles and Meyer, 2008; He et al., 2011). Typically, the black-and white Picasso sketch that depicts a mother holding and looking at her baby (Mikulincer et al., 2001) or attachment-related images such as photographs of a mother holding a baby are used (Bryant and Foord, 2016). In line with these previous studies, photographs that prime secure and insecure attachments were used for the non-verbally primed group in this study. For the verbally primed group, texts that explain and describe the photographs were used. This method is typically used in research that identifies differences between non-verbal and verbal cues (Peristeri et al., 2018; Radman et al., 2018). For Studies 1 and 2, we expected that the differences in self-esteem, interpersonal competence, and positive affect between secure and insecure attachment styles that had been primed by non-verbal cues would be greater than the differences between the two styles of attachment primed verbally.

\section{STUDY 1}

In Study 1, secure and insecure attachment styles were activated by non-verbal priming and verbal priming, and differences in self-esteem, interpersonal competence, and positive affect according to the activated attachment style were examined. Based on previous literature (Anders and Tucker, 2000), secure attachment is presumed to contain the following two core representations: (1) positive representation of oneself (e.g., "I must be a pretty good person; that must be why that a person is consistently interested in me and kind to me") and (2) positive representation of others (e.g., "People are trustworthy"). In other words, people with secure attachment are likely to have higher self-esteem and view others in a more positive light. They are also expected to be better at forming interpersonal relationships and experience positive emotions more often than people with insecure attachment (Levy et al., 1998).

However, given the importance of non-verbal interaction in attachment formation at the preverbal stage, non-verbal cues may have greater influence than verbal cues on multiple consequences and correlates of attachment (e.g., self-esteem, interpersonal competence, and positive affect). Accordingly, we sought to activate secure and insecure attachments through two priming conditions-non-verbal priming and verbal priming-and to examine the different impacts according to priming modality and attachment style. More specifically, we expected that the differences in self-esteem, interpersonal competence, and positive affect between the secure attachment group and the insecure attachment group would be greater when primed by non-verbal rather than verbal cues.

\section{Methods \\ Participants}

One hundred and seven undergraduates participated for course credit. Twelve participants who did not complete the questionnaire or failed to be primed were excluded, leaving a total of 93 participants ( 27 men, 66 women). The mean age was 22.4 years, ranging from 19 to 29 years $(S D=1.84)$.

\section{Experimental Design}

We employed a 2 (priming modality: non-verbal vs. verbal) $\times 2$ (attachment style: secure vs. insecure) factorial design. Participants were randomly assigned to one of four groups: secure attachment through non-verbal cues $(n=25)$, insecure attachment through non-verbal cues $(n=26)$, secure attachment through verbal cues $(n=22)$, and insecure attachment through verbal cues $(n=20)$. Our dependent variables were self-esteem, interpersonal competence, and positive affect.

\section{Measurement Tools \\ Scenario priming}

A sense of acceptance is considered to be a core element of attachment representation (Sarason et al., 1990). Based on this, 
we chose the contents of the scenarios for secure and insecure attachment styles. According to the sensory modality priming condition, the relative weights of the non-verbal and verbal cues of the significant other were assigned differently. Specifically, participants in the secure attachment condition were instructed to recall and describe an instance in which they were with a significant other who tends to be accepting and non-evaluative of them. They were also directed to recollect in detail what the non-verbal cues of the person were at that moment. In contrast, participants in the insecure attachment condition were instructed to recall and describe a moment when they were non-verbally rejected and discouraged by a significant other. For groups with secure and insecure attachments primed by verbal cues of the significant other, instructions for the nonverbal cue portion were changed to "recollect the content of his or her words in detail." By using guided imagery, albeit with differential priming through non-verbal or verbal cues of significant others for each group, we followed the standard research method employed in previous studies (Jakubiak and Feeney, 2016b; see Appendix).

\section{Self-esteem}

The Single-Item Self-Esteem Scale (Robins et al., 2001) was used to measure self-worth. A sample question is, "At this moment, I have high self-esteem," and responses were assessed on a fivepoint Likert scale $(1=$ Not at all, $5=$ Strongly agree $)$. The scale was chosen as an alternative to using the Rosenberg Self-Esteem Scale, which has a 10-item scale. Though shorter, the scale has strong convergent validity with the Rosenberg Self-Esteem Scale, as well as similar predictive validity (Robins et al., 2001).

\section{Interpersonal competence}

We used the Interpersonal Competence Questionnaire Scale (Buhrmester et al., 1988), which contains 31 items and five subscales on initiating relationships, self-disclosure, asserting displeasure with others' actions, providing emotional support, and managing interpersonal conflicts. Individual items are measured on a five-point Likert scale $(1=$ Not at all, $5=$ Strongly disagree). Scores on the five subscales $(\alpha=0.86)$ were summed to obtain an overall score; a higher score indicates greater interpersonal competence.

\section{Positive affect}

From the Scale of Positive and Negative Experience developed by Diener et al. (2009) to measure positive and negative experiences,

\footnotetext{
${ }^{1} \mathrm{~A}$ sample response by participants in the condition in which secure attachment was non-verbally primed is as follows: "When I was little, I hugged my mom, and took naps frequently. Through a window, the sunlight was coming in, and, largely, there was no conversation. With her eyes closed, my mom had fallen asleep. With my face buried against my mom's body, either I had been smelling her body, which I had liked, or I had been touching her chest or belly. My mom had mainly slept while making low breathing sounds. Because the breathing sounds were in a rhythmic cycle, in many cases I, too, fell asleep. It was the most peaceful time in my life." A sample response by participants in the condition in which insecurity was verbally primed is as follows: "When I was in my senior year of high school, because I was very sad, I telephoned home. I went up to the rooftop to make the call, because I was really sad. My mom, who had been listening for a long time, said, 'So what?' When I heard her words, I thought, 'Ah, I am the only one in the world. ..' After hearing her words I hung up the phone after saying, 'Is that so? It must be so. ... I will hang up, Mom."”
}

we used six items that measure positive experience. A sample item is, "Please circle how much you experience each of the following feelings or emotions right now at this moment," followed by six adjectives (joyful, happy, positive, contented, pleasant, and delighted). To capture subtle differences, the original five-point Likert scale for each item was expanded to a seven-point scale $(1=$ Very rarely or never, $7=$ Very often or always $)$. The scores of all items were summed $(\alpha=0.95)$, with a higher score indicating greater positive affect.

\section{Procedure}

After completing the informed consent form, each participant was taken to a separate space divided by partitions. Participants were randomly assigned to four groups, and corresponding scenarios were presented to each group. They were given $6 \mathrm{~min}$ to read the scenario and write about their recalled memories, after which they responded to questions about whether their recalled memories and emotions were (1) accurately recollected, (2) easily recollected, or (3) vividly called to mind even now, using a seven-point Likert scale $(1=$ Not at all, $7=$ Extremely; Baldwin and Sinclair, 1996). For a manipulation check, we only included data from participants who scored at least four points on three questions. Two raters read and evaluated participants' recalled memories. If their ratings did not coincide with each other, it was also regarded as a priming failure. After the priming manipulation, participants completed a questionnaire.

\section{Results}

We compared differences in self-esteem, interpersonal competence, and positive affect between the two groups that had activated secure and insecure attachments through non-verbal cues with the corresponding differences between the two groups that had activated secure and insecure attachments through verbal cues. For the purpose of this comparison, we performed a 2 (priming modality: non-verbal vs. verbal) $\times 2$ (attachment style: secure vs. insecure) analysis of variance. Both factors were between-subject variables. Figure 1 shows the means and standard errors for each dependent variable as a function of priming modality and attachment style.

\section{Self-Esteem}

The $2 \times 2$ ANOVA for self-esteem showed that there were no main effects of priming modality, $F<1.97, p=0.17$, $\eta^{2}=0.02$, and attachment style, $F<1, p=0.36, \eta^{2}=0.01$. As expected, however, there was a significant interaction between priming modality and attachment style, $F(1,91)=5.45$, $p=0.02, \eta^{2}=0.06$. As shown in Figure 1A, a significant difference in self-esteem was found between secure and insecure attachment groups primed by non-verbal cues, $t(51)=2.58$, $p=0.01$. More specifically, participants in the group in which secure attachment was primed by non-verbal cues $(M=3.60$, $S D=0.86)$ showed greater self-esteem than those in the group in which insecure attachment was primed $(M=3.04$, $S D=0.70)$. Conversely, there was no significant difference between the two attachment styles primed by verbal cues, $t(41)=-1.07, p=0.29$. 


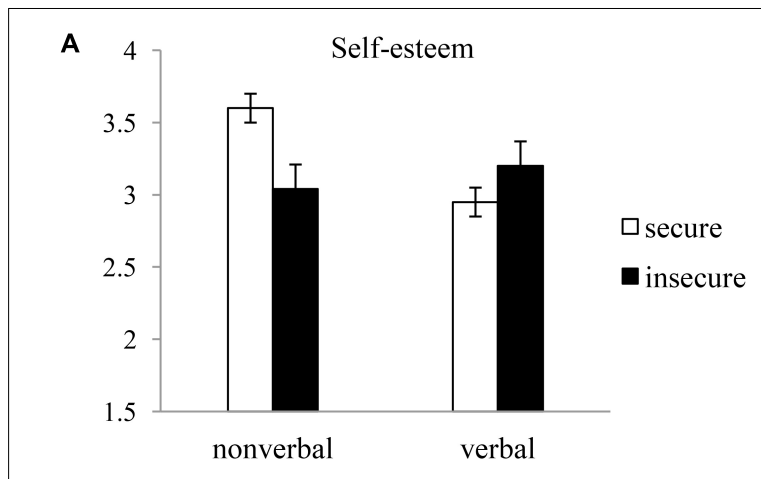

B 115 Interpersonal competency

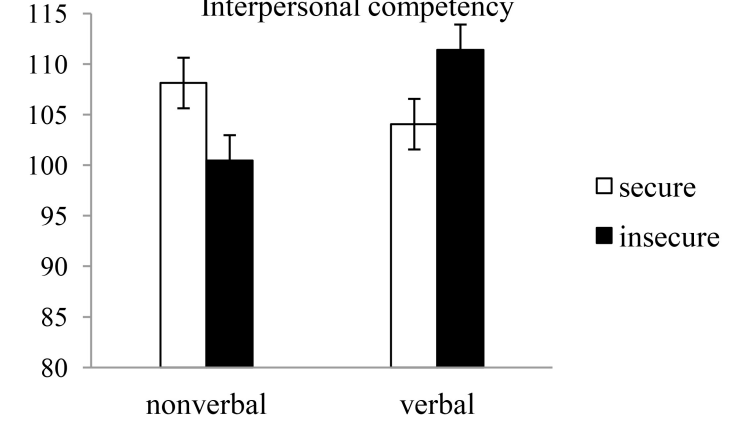

C

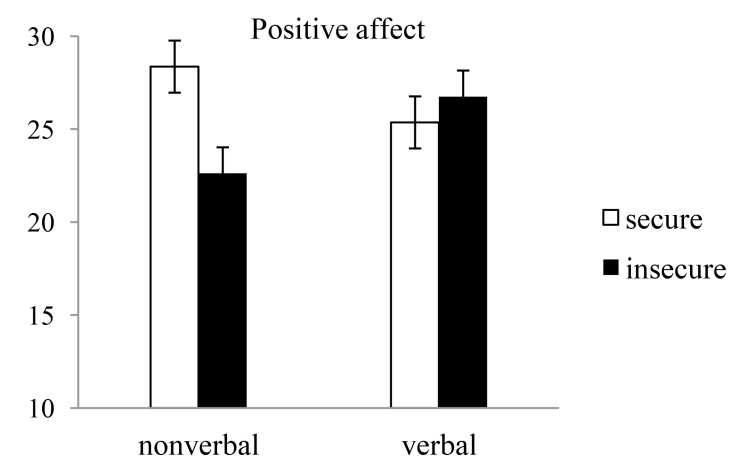

FIGURE 1 | Mean scores of (A) self-esteem, (B) interpersonal competency, and (C) positive affect against priming modality and primed attachment style (Study 1).

\section{Interpersonal Competence}

The $2 \times 2$ ANOVA for interpersonal competence showed that there were no main effects of priming modality, $F<1.8$, $p=0.19, \eta^{2}=0.02$, and attachment style, $F<1, p=0.95$, $\eta^{2}=0.00$. However, the interaction between priming modality and attachment style was significant, $F(1,89)=8.29, p=0.01$, $\eta^{2}=0.09$. As shown in Figure $\mathbf{1 B}$, there was a significant difference in interpersonal competence between the two attachment styles primed by non-verbal cues, $t(50)=2.11$, $p=0.04$. More specifically, participants in the group in which secure attachment was primed by non-verbal cues $(M=108.12$, $S D=13.00)$ showed greater interpersonal competence than those in the group in which insecure attachment was primed $(M=100.46, S D=12.90)$. On the other hand, there was no significant difference between the two attachment styles primed by verbal cues, $t(41)=-1.99, p=0.06$.

\section{Positive Affect}

The $2 \times 2$ ANOVA for positive affect showed that there were no main effects of priming modality, $F<1, p=0.70, \eta^{2}=0.00$, and attachment style, $F<2.5, p=0.14, \eta^{2}=0.02$. However, the interaction between priming modality and attachment style was significant, $F(1,91)=5.83, p=0.02, \eta^{2}=0.6$. As shown in Figure 1C, for the non-verbally primed condition, the secure attachment group $(M=28.36, S D=6.31)$ showed greater positive affect than the insecure attachment group $[M=22.62, S D=7.56$ ), $t(51)=2.80, p=0.01]$. Conversely, there was no significant difference between the two verbally primed attachment styles, $t(41)=-0.3, p=0.77$.

In summary, for the non-verbal priming condition, participants primed with secure attachment showed greater self-esteem, interpersonal competence, and positive affect than those primed with insecure attachment. On the other hand, no significant differences were found for the verbal priming condition. This suggests that the consequences of each attachment style are more apparent when it is activated by non-verbal than verbal cues.

However, this study has several limitations. First, the sample size was not sufficiently large. Second, each participant's attachment orientation was not measured. However, previous research has shown that participants' original attachment orientation is independent of the style of attachment primed (Carnelley and Rowe, 2007; Gillath et al., 2010; Luke et al., 2012). That is, our priming manipulations are based on the fact that even though people have an attachment orientation, most can change their attachment orientation over time and are sensitive to specific situations (Cozzarelli et al., 2003; Birnbaum et al., 2012; Hudson, 2016). If we compared participants' attachment orientation, however, we could determine whether it moderates the effects of the attachment primed. Third, the priming method might not be effective for activating non-verbal or verbal cues exclusively. Although we asked participants to concentrate on a significant other's non-verbal or verbal cues, there is a possibility that participants mixed the non-verbal and verbal cues when recollecting the memory of interaction with the significant other. Lastly, because we did not include a neutral condition, it is difficult to clearly determine the priming effects. If each of the primed attachment groups were compared to a neutral group, we could obtain a more valid test of the unique effects of securely and insecurely primed attachments. Accordingly, Study 2 aimed to close these gaps.

\section{STUDY 2}

As in Study 1, the main goals of Study 2 were to examine whether secure and insecure attachments are activated through non-verbal and verbal priming, and whether differences in self-esteem, interpersonal competence, and positive affect arose from the attachment style activated. To overcome the limitations of Study 1, we increased sample sizes and 
measured participants' attachment orientation. Also, for the non-verbal condition, photographs were used as representative, non-verbal stimuli. For the verbal condition, we used text that described each photograph. Finally, we included an attachment-neutral condition to examine the differences between the primed attachment groups and the neutral group. We anticipated that the differences in self-esteem, interpersonal competence, and positive affect between the secure and insecure attachment groups would be greater when the priming took place non-verbally than verbally.

\section{Methods \\ Participants}

Four hundred nine people participated in the online experiment. Because 10 participants answered the questionnaire insincerely or failed the priming, they were excluded from the analysis. Data for 399 participants (141 males, 258 females) were used. The mean age was 38.3 years, ranging from 19 to $49(S D=8.25)$.

\section{Experimental Design}

We employed a 2 (priming modality: non-verbal vs. verbal) $\times 3$ (attachment style: secure vs. insecure vs. neutral) factorial design. Participants were randomly assigned to one of six groups: secure attachment through non-verbal cues $(n=64)$, insecure attachment through non-verbal cues $(n=65)$, neutral through non-verbal cues $(n=68)$, secure attachment through verbal cues $(n=68)$, insecure attachment through verbal cues $(n=67)$, and neutral through verbal cues $(n=67)$. As dependent variables, self-esteem, interpersonal competence, and positive affect were measured in the same way as in Study 1.

\section{Measurement Tools \\ Non-verbal/verbal priming}

Based on the priming condition, photographs or words were presented in the middle of the computer screen. For the condition in which secure attachment was primed nonverbally, the photograph of a mother feeding her baby as they looked at each other was presented. For the condition in which insecure attachment was primed nonverbally, a photograph of a male holding a baseball bat and a girl curled up on the ground was presented. For the neutral nonverbal condition, a photograph of 12 interconnected gray heptagons was presented. In contrast, descriptions of the photographs were presented for the verbal priming conditions as follows: "A mother wearing a white shirt and white pants is sitting on a white mattress and feeding her baby boy, who is wearing diapers as they look at each other and smile." for the secure attachment condition, "A strong man's lower body is viewed from the rear. He is wearing white pants and holding a baseball bat in his right hand, and a girl who is wearing a white top and short blue pants is curled up on the floor in a corner." for the insecure attachment condition, and "Twelve overlapping gray heptagons are presented against a gray background." for the neutral condition. For all the conditions, we chose stimuli that are commonly used in research on attachment (Dalgleish et al., 2007; Li and Kato, 2011).

\section{Self-esteem, interpersonal competence, and positive affect}

The same procedures were used as in Study 1. The internal consistency of interpersonal competence was $\alpha=0.93$, and the scale of positive affect was $\alpha=0.97$.

\section{Adult attachment style}

To measure each participant's attachment orientation, the Experiences in Close Relationships-Revised Questionnaire (ECR$\mathrm{R}$; Fraley et al., 2000) was used. The scale contains 36 items and is divided into two subscales: anxiety attachment $(\alpha=0.92)$, which represents rejection or abandonment by others, and avoidance attachment $(\alpha=0.87)$, which measures discomfort related to becoming intimate with and relying on another person. The higher the total score $(\alpha=0.90)$, the greater the anxiety and avoidance triggered by attachment. Each item was rated on a five-point Likert scale ( $1=$ Not at all to $5=$ Strongly agree). A sample avoidance item is, "I prefer not to show others how I feel deep down"; a sample anxiety item is, "I worry about being rejected or abandoned."

\section{Procedure}

After completing the informed consent form, participants were presented with their respective group's photograph or words and asked to reflect on the following questions: (1) "At that moment, what is child feeling?"; (2) "What kind of a person will the child become in the future, and what kind of life will he or she have?" (Bowles and Meyer, 2008); and (3) "If I were that child, what emotion would I feel at that moment?" While looking at the photograph or reading the words, participants were asked to imagine the situation as deeply as possible. Participants in the neutral group were asked to observe or try to imagine the figures in as much detail as possible. Next, the secure and insecure attachment groups answered questions regarding the clarity, ease, and realism of their recalled memories and emotions on a seven-point Likert scale ( 1 = Not at all, 7 = Extremely; Baldwin and Sinclair, 1996). After this, participants completed a questionnaire that measures self-esteem, interpersonal competence, and positive affect. Lastly, to eliminate the priming effect and diffuse any feelings of attention, participants were asked to solve 10 arithmetic problems (e.g., 27+15, 66-7). Afterward, each participant's attachment orientation was measured.

\section{Results}

We compared differences in self-esteem, interpersonal competence, and positive affect between (a) the three groups in which secure attachment, insecure attachment, and a neutral condition were activated with non-verbal cues and (b) the three corresponding groups activated with verbal cues. For the purpose of this comparison, we performed a 2 (priming modality: non-verbal vs. verbal) $\times 3$ (attachment style: secure vs. insecure vs. neutral) ANOVA on each of the dependent variables-selfesteem, interpersonal competence, and positive affect. Both factors were between-subject variables. Prior to the analysis, we examined the homogeneity of participants in the six groups in terms of their attachment orientation scores, which were found to not vary across all of the six groups, $F(5,393)=0.33$, 


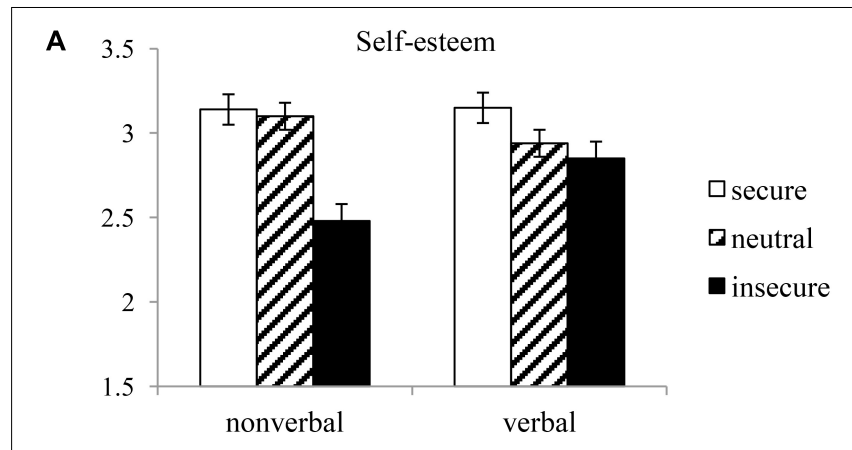

B 105 Interpersonal competency

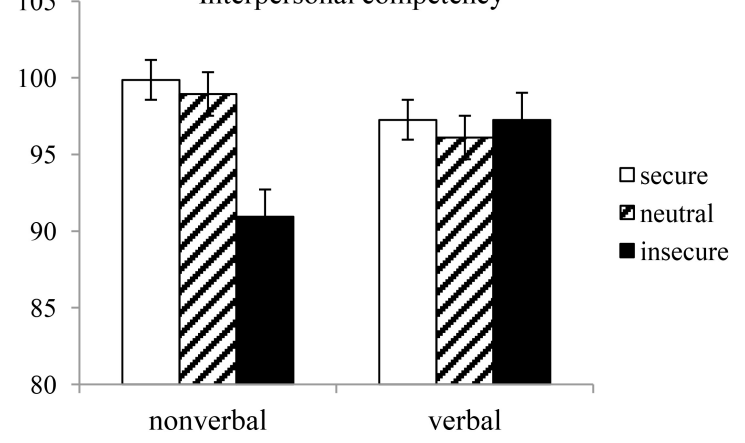

C

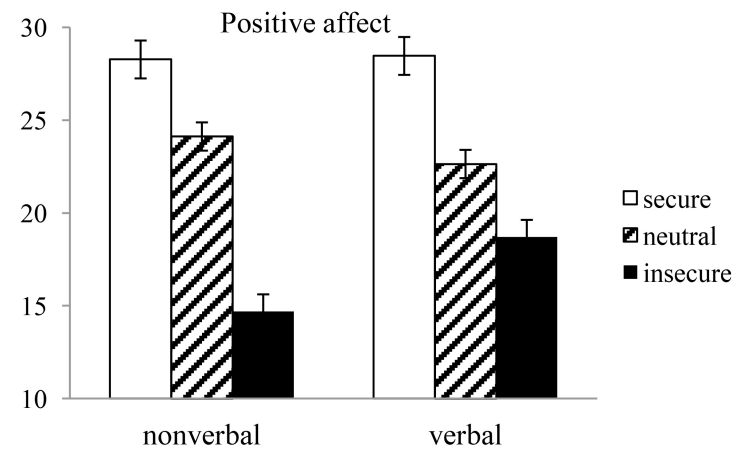

FIGURE 2 | Mean scores of (A) self-esteem, (B) interpersonal competency, and (C) positive affect against priming modality and primed attachment style (Study 2).

$p=0.89$. In addition, an ANOVA was performed, controlling for attachment orientation scores as the covariates. Figure 2 shows the means and standard errors for each dependent variable as a function of priming modality and attachment style.

\section{Self-Esteem}

The $2 \times 3$ ANCOVA for self-esteem showed that the main effect of attachment style was significant, $F(1,392)=13.91, p<0.00$, $\eta^{2}=0.07$, but the main effect of priming modality was not, $F<1.03, p=0.31, \eta^{2}=0.00$. Self-esteem was greater in the following order: secure attachment group $(M=3.14, S D=0.79)$, neutral group $(M=3.02, S D=0.72)$, and insecure attachment group $(M=2.67, S D=0.90)$. As expected, there was a significant interaction between priming modality and attachment style,
$F(2,392)=4.33, p=0.01, \eta^{2}=0.02$, which is the crucial part of our analysis in Study 2. As displayed in Figure 2A, a Bonferroni post hoc analysis showed that self-esteem was greater for the group in which secure attachment was primed non-verbally $(M=3.14, S D=0.79)$ than for the group in which insecure attachment was primed non-verbally $(M=2.48, S D=0.88)$, $p=0.00$. Also, self-esteem was greater for the non-verbal neutral group $(M=3.10, S D=0.75)$ than for the group in which insecure attachment was primed non-verbally $(M=2.48, S D=0.88)$, $p=0.00$. In contrast, no significant difference was found between secure attachment, insecure attachment, and neutral groups that were primed verbally.

\section{Interpersonal Competence}

The $2 \times 3$ ANCOVA for interpersonal competence showed that the main effect of attachment style was significant, $F(1,392)=3.53, p=0.03, \eta^{2}=0.02$, but the main effect of priming modality was not, $F<0.08, p=0.78, \eta^{2}=0.00$. Interpersonal competence scores were greater in the following order: secure attachment group $(M=98.52, S D=14.15)$, neutral group $(M=97.53, S D=13.32)$, and insecure attachment group $(M=94.14, S D=17.65)$. As expected, there was a significant interaction between priming modality and attachment style, $F(2,392)=4.60, p=0.01, \eta^{2}=0.02$. As displayed in Figure 2B, a Bonferroni post hoc analysis showed that interpersonal competence was greater for the group in which secure attachment was primed non-verbally $(M=99.86, S D=14.98)$ than for the group in which insecure attachment was primed non-verbally $(M=90.94, S D=19.99), p=0.01$. Also, interpersonal competence was greater for the non-verbal neutral group $(M=98.94$, $S D=13.70$ ) than for the group in which insecure attachment was primed non-verbally $(M=90.94, S D=19.99), p=0.03$. In contrast, no significant difference was found between secure attachment, insecure attachment, and neutral groups that were primed verbally.

\section{Positive Affect}

The $2 \times 3$ ANCOVA for positive affect showed that the main effect of attachment style was significant, $F(1,392)=83.19$, $p=0.00, \eta^{2}=0.30$, but the main effect of priming modality was not, $F<1.7, p=0.20, \eta^{2}=0.004$. Positive affect was greater in the following order: secure attachment group $(M=28.36$, $S D=8.02)$, neutral group $(M=23.39, S D=6.25)$, and insecure attachment group $(M=16.73, S D=8.50)$. As expected, there was a significant interaction between priming modality and attachment style, $F(2,392)=4.96, p=0.01, \eta^{2}=0.03$. As displayed in Figure 2C, a Bonferroni post hoc analysis showed that for the non-verbal condition, positive affect was greater for the secure attachment group $(M=28.27, S D=8.16)$ than for the neutral group $(M=24.21, S D=6.31), p=0.03$, which in turn greater than for the insecure attachment group $(M=14.69, S D=7.52)$, $p=0.00$. In a similar way, for the verbal condition, positive affect was greater for the secure attachment group $(M=28.46$, $S D=7.94)$ than for the neutral group $(M=22.64, S D=6.14)$, $p=0.00$, which in turn greater than for the insecure attachment group $(M=18.70, S D=8.98), p=0.00$. However, the significant priming modality $\times$ attachment style interaction suggests that the 
effect of attachment style on positive affect appears prominent for the non-verbal priming condition as compared to that for the verbal priming condition.

In summary, for the non-verbal priming condition, the insecure attachment group reported lower self-esteem and interpersonal competence than the secure attachment group and the neutral group. In contrast, for the verbal priming condition, no significant differences in self-esteem and interpersonal competence were found between the secure attachment group, the insecure attachment group, and the neutral group. For both priming conditions, the insecure attachment group reported lower positive affect than the neutral group, which in turn lower than the secure attachment group. However, the differences in positive affect between the insecure attachment group and the other groups were greater for the non-verbal priming condition than for the verbal priming condition. Overall our results suggest that priming attachment non-verbally rather than verbally is more useful for observing the characteristics of each type of attachment.

\section{DISCUSSION}

Across two studies, we tested the effect of non-verbal priming on the activation of secure and insecure attachment styles. Specifically, the relative benefit of non-verbal priming compared to verbal priming was observed in the differences found in selfesteem, interpersonal competence, and positive affect according to attachment style.

In Study 1, through the use of scenario priming in the nonverbal condition, we emphasized the significant other's gaze, voice, and touch to activate attachment styles. By revealing the relationship between secure attachment and various nonverbal cues that engage visual, tactile, and auditory senses, our results go one step beyond the previous finding that a single non-verbal cue-physical contact-activates secure attachment (Debrot et al., 2013; Jakubiak and Feeney, 2016a). However, in using this method the possibility arises that when a participant recollects the interaction with a significant other, the sense of attachment arises from a mix of non-verbal and verbal cues. Since memory is composed of both cues, it can be hard to distinguish between them.

To compensate for this possibility, in Study 2 attachment was primed using a standard method for comparing nonverbal and verbal cues: presenting photographs in the nonverbal condition and words that describe the photographs in the verbal condition (Snodgrass and Vanderwart, 1980). As a result, the group with secure attachment primed by nonverbal cues showed higher self-esteem, had more confidence in interpersonal relationships, and experienced greater positive affect than the group with insecure attachment primed by non-verbal cues. This finding is consistent with the results of previous research that used priming without distinguishing between non-verbal and verbal channels (Downey and Feldman, 1996; Murray et al., 2002; Pickett et al., 2004; Anthony et al., 2007). In contrast, differences between the groups that were primed verbally were either not significant or relatively smaller compared to the non-verbal condition. More specifically, if we consider the two attachment groups and the neutral group in the non-verbal priming condition, the insecure attachment group reported significantly lower self-esteem and interpersonal competence compared to the secure attachment group and the neutral group. In contrast, between the secure attachment group and the neutral group, no significant differences were found when measuring self-esteem and interpersonal competence. Why is the difference between the secure attachment group and neutral group relatively smaller compared to that between the insecure attachment group and neutral group? This may be attributable to the percentage of the attachment style in the general population. Several studies indicate that more than $60 \%$ of people have a secure attachment style (Campos et al., 1983; Hazan and Shaver, 1987; Collins and Read, 1990; Mikulincer, 1995). Based on this finding, it is plausible to assume that the neutral group was closer to the secure attachment group than to the insecure attachment group. On the other hand, positive affect, regardless of the priming condition, was greater in the following order: secure attachment group, neutral group, and insecure attachment group. This may be because the measurement variable is affect rather than thinking about oneself in terms of self-esteem and interpersonal competence. Sroufe and Waters (1977) stress the importance of emotions in attachment, because the goal of attachment is "felt security." In addition, attachment is the primary experience in learning how to regulate emotions (Schore, 2003). Considering these points, positive affect seems to be even more connected with attachment than self-esteem and interpersonal competence, in which such beliefs as "My self-esteem is high" and "I can do well with my interpersonal relationships" are emphasized. As a result, it seems that attachment priming had more impact on affective than cognitive measurement. Future research may investigate the relationship between primed attachment styles and emotion, including positive and negative affect.

Also, why did a significant difference occur more frequently when the attachment was primed non-verbally than verbally? There are several possibilities. First, the vividness and intensity of attachment activated by non-verbal cues may have been higher and, in turn, better at evoking sensory experience than verbal cues (DeVries et al., 2003; Ditzen et al., 2008). In support of this, Willander and Larsson (2008) showed that participants in an odor imagery group who were asked to imagine the stimuli's odor had more strongly activated sensory modalities-such as visual, olfactory, and auditory senses - than participants in a verbal group who were only presented with words like "tobacco," "beer," and "soap." Similarly, Jakubiak and Feeney (2016b) found that imagining being touched buffered stress and pain more than verbal support. In our study, non-verbal and verbal stimuli constituted a between-subject variable; thus, it was not possible to explore how each individual experienced the intensity of schemas differently according to their activation under non-verbal or verbal conditions. In the case of respondents who scored at least four-points on the manipulation check, it was deemed that the relevant schema was activated and the analysis was conducted. However, this issue is worth considering in greater depth in a subsequent study. 
Second, because of the nature of verbal cues, there may have been a relatively noticeable difference between the groups primed by non-verbal cues. For instance, when one actually receives or imagines the verbal support of a significant other in a stressful situation, one may worry about being evaluated by the other (Bolger and Amarel, 2007; Uchino, 2009; Feeney and Thrush, 2010; Taylor et al., 2010; Jakubiak and Feeney, 2016b). Verbal support focuses on one's ability to address the stressor or problem (e.g., "It's okay-you can do better next time"), which can tacitly pressure one into thinking, after being comforted, that one must perform well to maintain the approval of the attachment figure. Further, verbal support may threaten self-efficacy by being construed as support that is provided due to one's vulnerability (Jakubiak and Feeney, 2016b). In contrast, non-verbal cues are used to convey valence without articulating a specific message. Therefore, these cues seldom lead to pressure or decreased self-efficacy. Perhaps due to these differences in the nature of verbal and non-verbal cues, secure attachment activated by verbal priming may not have as great an effect as secure attachment activated by non-verbal priming. However, it is still difficult to explain why the differences between verbally primed groups are smaller than those between nonverbally primed groups. Thus, we cannot assume that verbal priming is ineffective.

We do not mean to suggest that non-verbal cues provide the only access to the process of forming and activating attachment representations. Verbal and non-verbal cues are not separate in everyday life, because non-verbal behavior unconsciously gives rise to verbal expression, and verbal behavior unconsciously gives rise to non-verbal reactions (Knapp et al., 2013). Verbal and nonverbal cues can convey emotions, attitudes, personality traits, and reactions most effectively when combined to form a holistic interaction system. Therefore, we suggest that follow-up studies proceed from a comprehensive point of view that takes into account the nature of non-verbal cues.

The methodological limitations of this study are as follows. First, subsequent studies should pay more attention to measuring non-verbal cues. Study 1 used written instructions and guided imagery to prime non-verbal cues, which is an experimental method based on previous studies. During the priming procedure, however, there is a possibility that the non-verbal and verbal clues mixed. To overcome this limitation, in Study 2 we presented photographs and the words that describe them; this method is used frequently in non-verbal research. However, again, the instructions to participants had to use language. Also, although the photographs and words that are generally used in non-verbal research are concrete objects such as a table, spider, and bus (Snodgrass and Vanderwart, 1980), as an abstract concept, "attachment" is difficult to accurately match with photographs and their descriptions in words. In future research, it will be worth considering whether there is a method for priming with non-verbal stimuli by employing physiological and physical conditions and excluding the use of language.

Second, subsequent studies will require more fine-grained attention to insecure attachment, which can be further divided into avoidant and anxious attachment. However, in this study, attachment was divided into only two styles: secure and insecure.
This was because it is an exploratory study of the importance of non-verbal cues in attachment, which has rarely been discussed; thus, we focused on secure and insecure attachment before examining them in detail. Moreover, if we consider the characteristics of insecure attachment, it would be difficult to divide it into avoidance attachment and anxiety attachment through the use of priming methods only. This is because both attachment styles arise from the same failure to form a secure attachment to primary caregivers, but the differences are found in the child's temperament, which can be regarded as the participant's temperament. The DSM-5 includes two disorders in relation to attachment: Reactive Attachment Disorder, which corresponds to avoidance attachment, and Disinhibited Social Engagement Disorder, which corresponds to anxiety attachment. Children with both of these disorders experience abusive or neglectful interactions with caregivers, but it is assumed that children exhibit different reactions and impairments due to differences in inherent temperament (American Psychiatric Association [APA], 2013; Gabbard, 2014). More specifically, children who have Reactive Attachment Disorder have an innately introverted and overly sensitive temperament, and react in an avoidant manner when they experience abusive or extremely unhealthy interactions with the caregiver. In contrast, children who exhibit Disinhibited Social Engagement Disorder are innately extroverted and temperamentally predisposed to seek stimuli; it is assumed that they react with excessive sociality and impulsive behavior (Lemelin et al., 2002; Zeanah and Gleason, 2010). Thus, priming alone-such as presenting an insecure attachment figure or evoking memories of abusive interactions-may limit the ability to subdivide insecure attachment. In future research, a nuanced research design that considers the temperament of each participant may be required.

Finally, the secure attachment activated in this study is a state attachment representation. Although individuals have secure and insecure attachment representations as traits, they can have also secure and insecure attachment representations as states according to priming or specific circumstances (Baldwin and Fehr, 1995; Baldwin et al., 1996). Therefore, further investigation is required to determine whether the same pattern of results is present in the case of trait attachment representations.

\section{ETHICS STATEMENT}

This study was carried out in accordance with the recommendations of the Yonsei University Research Ethics Committee. The protocol was approved by the Yonsei University Institutional Review Board. Participants gave written informed consent in accordance with the Declaration of Helsinki.

\section{AUTHOR CONTRIBUTIONS}

SS and YS developed the study concept and design. SS collected the data and performed the data analysis under the supervision of YS. SS drafted the manuscript. JS provided critical revisions. All the authors approved the final version of the manuscript for submission. 


\section{REFERENCES}

Ainsworth, M. D. S. (1969). Object relations, dependency, and attachment: a theoretical review of the infant-mother relationship. Child Dev. 40, 969-1025. doi: $10.2307 / 1127008$

Ainsworth, M. D. S., Blehar, M. C., Waters, E., and Wall, S. (1978/2015). Patterns of Attachment: Assessed in the Strange Situation and at Home. Hillsdale, NJ: Erlbaum.

American Psychiatric Association [APA] (2013). Diagnostic and Statistical Manual of Mental Disorders, DSM-5, 5th Edn. Washington, DC: American Psychiatric Association. doi: 10.1176/appi.books.97808904 25596

Anders, S. L., and Tucker, J. S. (2000). Adult attachment style, interpersonal communication competence, and social support. Pers. Relationsh. 7, 379-389. doi: $10.1002 /$ cpp. 1849

Anthony, D. B., Wood, J. V., and Holmes, J. G. (2007). Testing sociometer theory: self-esteem and the importance of acceptance for social decision-making. J. Exp. Soc. Psychol. 43, 425-432. doi: 10.1016/j.jesp.2006.03.002

App, B., McIntosh, D. N., Reed, C. L., and Hertenstein, M. J. (2011). Nonverbal channel use in communication of emotion: how may depend on why. Emotion 11, 603-617. doi: 10.1037/a0023164

Baldwin, M. W., and Fehr, B. (1995). On the instability of attachment style ratings. Pers. Relationsh. 2, 247-261. doi: 10.1016/j.psychres.2014.04.027

Baldwin, M. W., Keelan, J. P. R., Fehr, B., Enns, V., and Koh-Rangarajoo, E. (1996). Social-cognitive conceptualization of attachment working models: availability and accessibility effects. J. Pers. Soc. Psychol. 71, 94-109. doi: 10.1037/00223514.71.1.94

Baldwin, M. W., and Sinclair, L. (1996). Self-esteem and "if.then" contingencies of interpersonal acceptance. J. Pers. Soc. Psychol. 71, 1130-1141. doi: 10.1037/ 0022-3514.71.6.1130

Beebe, B., Jaffe, J., Lachmann, F., Feldstein, S., Crown, C., and Jasnow, M. (2000). Systems models in development and psychoanalysis: the case of vocal rhythm coordination and attachment. Infant Ment. Health J. 21, 99-122. doi: 10.1002/ (SICI)1097-0355(200001/04)21:1/2<99::AID-IMHJ11>3.0.CO;2-\#

Beijersbergen, M. D., Juffer, F., Bakermans-Kranenburg, M. J., and van IJzendoorn, M. H. (2012). Remaining or becoming secure: parental sensitive support predicts attachment continuity from infancy to adolescence in a longitudinal adoption study. Dev. Psychol. 48, 1277-1283. doi: 10.1037/a0027442

Birnbaum, G. E., Simpson, J. A., Weisberg, Y. J., Barnea, E., and Assulin-Simhon, Z. (2012). Is it my overactive imagination? The effects of contextually activated attachment insecurity on sexual fantasies. J. Soc. Pers. Relationsh. 29, 1131-1152. doi: $10.1177 / 0265407512452978$

Bolger, N., and Amarel, D. (2007). Effects of social support visibility on adjustment to stress: experimental evidence. J. Pers. Soc. Psychol. 92, 458-475. doi: 10.1037/ 0022-3514.92.3.458

Bowlby, J. (1969). Attachment and Loss, Volume 1 Attachment. New York, NY: BasicBooks.

Bowlby, J. (1973). Attachment and Loss: Volume 2 Separation: Anxiety and Anger. New York, NY: Basic Books.

Bowles, D. P., and Meyer, B. (2008). Attachment priming and avoidant personality features as predictors of social-evaluation biases. J. Pers. Disord. 22, 72-88. doi: 10.1521 /pedi.2008.22.1.72

Bryant, R. A., and Foord, R. (2016). Activating attachments reduces memories of traumatic images. PLoS One 11:e0162550. doi: 10.1371/journal.pone.0162550

Buck, R. (1984). The Communication of Emotion. New York, NY: Guilford Press.

Buhrmester, D., Furman, W., Wittenberg, M. T., and Reis, H. T. (1988). Five domains of interpersonal competence in peer relationships. J. Pers. Soc. Psychol. 55, 991-1008. doi: 10.1037/0022-3514.55.6.991

Campos, J., Barrett, K., Lamb, M., Goldsmith, H. H., and Sternberg, C. (1983). "Socioemotional development," in Handbook of Child Psychology, volume 2; Infancy and Developmental Psychobiology, eds M. M. Haith and J. J. Campos (New York, NY: Wiley), 783-915.

Canterberry, M., and Gillath, O. (2013). Neural evidence for a multifaceted model of attachment security. Int. J. Psychophysiol. 88, 232-240. doi: 10.1016/j. ijpsycho.2012.08.013

Carnelley, K. B., and Rowe, A. C. (2007). Repeated priming of attachment security influences later views of self and relationships. Pers. Relationsh. 14, 307-320. doi: $10.1111 /$ j.1475-6811.2007.00156.x
Chaiken, S., and Eagly, A. H. (1976). Communication modality as a determinant of message persuasiveness and message comprehensibility. J. Pers. Soc. Psychol. 34, 605-614. doi: 10.1037/0022-3514.34.4.605

Collins, N. L., and Feeney, B. C. (2000). A safe haven: an attachment theory perspective on support seeking and caregiving in intimate relationships. J. Pers. Soc. Psychol. 78, 1053-1073. doi: 10.1037/0022-3514.78. 6.1053

Collins, N. L., and Read, S. J. (1990). Adult attachment, working models, and relationship quality in dating couples. J. Pers. Soc. Psychol. 58, 644-663. doi: 10.1037/0022-3514.58.4.644

Cozzarelli, C., Karafa, J. A., Collins, N. L., and Tagler, M. J. (2003). Stability and change in adult attachment styles: associations with personal vulnerabilities, life events, and global construals of self and others. J. Soc. Clin. Psychol. 22, 315-346. doi: 10.1521 /jscp.22.3.315.22888

Dalgleish, T., Williams, J. M. G., Golden, A.-M. J., Perkins, N., Barrett, L. F., Barnard, P. J., et al. (2007). The effects of experimentally induced attachment security on children's fear reactions. J. Exp. Psychol. Gen. 136, 23-42. doi: 10.1037/0096-3445.136.1.23

Darwin, C. (1872/1998). The Expression of the Emotions in Man and Animals. New York, NY: Oxford University Press.

Debrot, A., Schoebi, D., Perrez, M., and Horn, A. B. (2013). Touch as an interpersonal emotion regulation process in couples' daily lives: the mediating role of psychological intimacy. Pers. Soc. Psychol. Bull. 39, 1373-1385. doi: 10.1177/0146167213497592

DeVries, A. C., Glasper, E. R., and Detillion, C. E. (2003). Social modulation of stress responses. Physiol. Behav. 79, 399-407. doi: 10.1016/S0031-9384(03) 00152-5

Diener, E., Wirtz, D., Biswas-Diener, R., Tov, W., Kim-Prieto, C., Choi, D. W., et al. (2009). "New measures of well-being," in Assessing Well-Being: The Collected Works, ed. E. Diener (Dordrecht: Springer), 247-266.

Ditzen, B., Hoppman, C., and Klumb, P. (2008). Positive couple interactions and daily cortisol: on the stress-protecting role of intimacy. Psychosom. Med. 70, 883-889. doi: 10.1097/PSY.0b013e318185c4fc

Ditzen, B., Neumann, I. D., Bodenmann, G., von Dawans, B., Turner, R. A., Ehlert, U., et al. (2007). Effects of different kinds of couple interaction on cortisol and heart rate responses to stress in women. Psychoneuroendocrinology 32, 565-574. doi: 10.1016/j.psyneuen.2007.03.011

Downey, G., and Feldman, S. I. (1996). Implications of rejection sensitivity for intimate relationships. J. Pers. Soc. Psychol. 70, 1327-1343. doi: 10.1037/00223514.70.6.1327

Ekman, P., and Friesen, W. V. (1975). Unmasking the Face: A Guide to Recognizing Emotions from Facial Cues. Englewood Cliffs, NJ: Prentice Hall.

Feeney, B. C., and Kirkpatrick, L. A. (1996). Effects of adult attachment and presence of romantic partners on physiological responses to stress. J. Pers. Soc. Psychol. 70, 255-270. doi: 10.1037/0022-3514.70.2.255

Feeney, B. C., and Thrush, R. L. (2010). Relationship influences on exploration in adulthood: the characteristics and function of a secure base. J. Pers. Soc. Psychol. 98, 57-76. doi: 10.1037/a0016961

Fonagy, P. (2001). Attachment Theory and Psychoanalysis. New York, NY: Other Press.

Fraley, R. C., and Shaver, P. R. (1998). Airport separations: a naturalistic study of adult attachment dynamics in separating couples. J. Pers. Soc. Psychol. 75, 1198-1212. doi: 10.1037/0022-3514.75.5.1198

Fraley, R. C., Waller, N. G., and Brennan, K. A. (2000). An item response theory analysis of self-report measures of adult attachment. J. Pers. Soc. Psychol. 78, 350-365. doi: 10.1037/0022-3514.78.2.350

Gabbard, G. O. (2014). Psychodynamic Psychiatry in Clinical Practice, 5th Edn. Washington, DC: American Psychiatric Publishing.

Gillath, O., Sesko, A. K., Shaver, P. R., and Chun, D. S. (2010). Attachment, authenticity, and honesty: dispositional and experimentally induced security can reduce self-and other-deception. J. Pers. Soc. Psychol. 98, 841-855. doi: $10.1037 / \mathrm{a} 0019206$

Gunes, H., Piccardi, M., and Pantic, M. (2008). "From the Lab to the real world: affect recognition using multiple cues and modalities," in Affective Computing: Focus on Emotion Expression, Synthesis, and Recognition, (Vienna: In Tech Education and Publishing). doi: 10.5772/6180

Hazan, C., and Shaver, P. (1987). Romantic love conceptualized as an attachment process. J. Pers. Soc. Psychol. 52, 511-524. doi: 10.1037/0022-3514.52.3.511 
Hazan, C., and Shaver, P. R. (1990). Love and work: an attachment-theoretical perspective. J. Pers. Soc. Psychol. 59, 270-280. doi: 10.1037/0022-3514.59.2.270

Hazan, C., and Zeifman, D. (1994). Sex and the psychological tether. Adv. Pers. Relationsh. 5, 151-177. doi: 10.1037/a0023838

He, J., Li, N., and Li, T. (2011). Adult attachment and incidental memory for emotional words. Interpersona 5(Suppl.1), 1-20. doi: 10.5964/ijpr.v5isupp1.79

Hudson, N. W. (2016). The Impact of Attachment Anxiety on Susceptibility to False Memories. Ph.D. dissertation, University of Illinois at Urbana-Champaign, Champaign, IL.

Jakubiak, B. K., and Feeney, B. C. (2016a). A sense of security: touch promotes state attachment security. Soc. Psychol. Pers. Sci. 7, 745-753. doi: 10.1177/ 1948550616646427

Jakubiak, B. K., and Feeney, B. C. (2016b). Keep in touch: the effects of imagined touch support on stress and exploration. J. Exp. Soc. Psychol. 65, 59-67. doi: 10.1016/j.jesp.2016.04.001

Knapp, M. L., Hall, J. A., and Horgan, T. G. (2013). Nonverbal Communication in Human Interaction. Boston, MA: Cengage Learning.

Lemelin, J. P., Tarabulsy, G. M., and Provost, M. A. (2002). Relations between measures of irritability and contingency detection at 6 months. Infancy 3 , 543-554. doi: 10.1207/S15327078IN0304_08

Levy, K. N., Blatt, S. J., and Shaver, P. R. (1998). Attachment styles and parental representations. J. Pers. Soc. Psychol. 74, 407-419. doi: 10.1037/0022-3514. 74.2 .407

Li, T., and Kato, K. (2011). The affective component of secure base schema in a Japanese and a Chinese sample: evidence from affective priming paradigm. Interpersona 5(Suppl.1), 38-61. doi: 10.5964/ijpr. v5isupp 1.81

Luke, M. A., Sedikides, C., and Carnelley, K. (2012). Your love lifts me higher! The energizing quality of secure relationships. Pers. Soc. Psychol. Bull. 38, 721-733. doi: $10.1177 / 0146167211436117$

Mahler, M. S., Pine, F., and Bergman, A. (1975). The Psychological Birth of the Human Infant: Symbiosis and Individuation, Vol. 3. New York, NY: Basic Books.

Mickelson, K. D., Kessler, R. C., and Shaver, P. R. (1997). Adult attachment in a nationally representative sample. J. Pers. Soc. Psychol. 73, 1092-1106. doi: 10.1037/0022-3514.73.5.1092

Mikulincer, M. (1995). Attachment style and the mental representation of the self. J. Pers. Soc. Psychol. 69, 1203-1215. doi: 10.1037/0022-3514.69. 6.1203

Mikulincer, M., Gillath, O., and Shaver, P. R. (2002). Activation of the attachment system in adulthood: threat-related primes increase the accessibility of mental representations of attachment figures. J. Pers. Soc. Psychol. 83, 881-895. doi: 10.1037/0022-3514.83.4.881

Mikulincer, M., Hirschberger, G., Nachmias, O., and Gillath, O. (2001). The affective component of the secure base schema: affective priming with representations of attachment security. J. Pers. Soc. Psychol. 81, 305-321.

Mikulincer, M., and Shaver, P. R. (2004). "Security-based self-representations in adulthood," in Adult Attachment: Theory, Research, and Clinical Implications, eds W. S. Rholes and J. A. Simpson (New York, NY: Guilford Press).

Mikulincer, M., and Shaver, P. R. (2007). Boosting attachment security to promote mental health, prosocial values, and inter-group tolerance. Psychol. Inq. 18, 139-156. doi: 10.1080/10478400701512646

Mikulincer, M., and Shaver, P. R. (2012). Adult attachment orientations and relationship processes. J. Fam. Theory Rev. 4, 259-274. doi: 10.1111/j.17562589.2012.00142.x

Mikulincer, M., and Shaver, P. R. (2016). Attachment in Adulthood: Structure, Dynamics, and Change, 2nd Edn. New York, NY: Guilford.

Mikulincer, M., and Shaver, P. R. (2018). Attachment orientations and emotion regulation. Curr. Opin. Psychol. 25, 6-10. doi: 10.1016/j.copsyc.2018.02.006

Mikulincer, M., Shaver, P. R., Gillath, O., and Nitzberg, R. A. (2005). Attachment, caregiving, and altruism: boosting attachment security increases compassion and helping. J. Pers. Soc. Psychol. 89, 817-839. doi: 10.1037/0022-3514.89.5.817

Murray, S. L., Rose, P., Bellavia, G. M., Holmes, J. G., and Kusche, A. G. (2002). When rejection stings: how self-esteem constrains relationship- enhancement processes. J. Pers. Soc. Psychol. 83, 556-573. doi: 10.1037/0022-3514.83. 3.556
Niedenthal, P. M., Brauer, M., Robin, L., and Innes-Ker, Å. H. (2002). Adult attachment and the perception of facial expression of emotion. J. Pers. Soc. Psychol. 82, 419-433. doi: 10.1037/0022-3514.82.3.419

Pally, R. (2008). A primary role for nonverbal communication in psychoanalysis. Psychoanal. Inq. 21, 71-93. doi: 10.1080/07351692109348924

Pascuzzo, K., Cyr, C., and Moss, E. (2013). Longitudinal association between adolescent attachment, adult romantic attachment, and emotion regulation strategies. Attach. Hum. Dev. 15, 83-103. doi: 10.1080/14616734.2013.745713

Peristeri, E., Tsimpli, I. M., Sorace, A., and Tsapkini, K. (2018). Language interference and inhibition in early and late successive bilingualism. Bilingualism 21, 1009-1034. doi: 10.1017/S1366728917000372

Pickett, C. L., Gardner, W. L., and Knowles, M. (2004). Getting a cue: the need to belong and enhanced sensitivity to social cues. Pers. Social Psychol. Bull. 30, 1095-1107. doi: 10.1177/0146167203262085

Radman, N., Britz, J., Buetler, K., Weekes, B. S., Spierer, L., and Annoni, J. M. (2018). Dorsolateral prefrontal transcranial direct current stimulation modulates language processing but does not facilitate overt second language word production. Front. Neurosci. 12:490. doi: 10.3389/fnins.2018.00490

Ravitz, P., Maunder, R., Hunter, J., Sthankiya, B., and Lancee, W. (2010). Adult attachment measures: a 25-year review. J. Psychosom. Res. 69, 419-432. doi: 10.1016/j.jpsychores.2009.08.006

Riggio, R. E. (2006). "Nonverbal skills and abilities," in The Sage Handbook of Nonverbal Communication, eds V. L. Manusov and M. L. Patterson (Thousand Oaks, CA: Sage Publications), 79-95. doi: 10.4135/9781412976152.n5

Robins, R. W., Hendin, H. M., and Trzesniewski, K. H. (2001). Measuring global self-esteem: construct validation of a single-item measure and the Rosenberg Se lf-Esteem Scale. Pers. Soc. Psychol. Bull. 27, 151-161. doi: 10.1177/ 0146167201272002

Sarason, B. R., Pierce, G. R., and Sarason, I. G. (1990). "Social support: the sense of acceptance and the role of relationships," in Social Support: An Interactional View, eds B. R. Sarason I, G. Sarason, and G. R. Pierce (New York, NY: Wiley), 97-128.

Scherer, K. R. (1995). Expression of emotion in voice and music. J. Voice 9, 235-248. doi: 10.1016/S0892-1997(05)80231-0

Schore, A. N. (2003). Affect Regulation and the Repair of the Self. New York, NY: Norton.

Selcuk, E., Zayas, V., Günaydin, G., Hazan, C., and Kross, E. (2012). Mental representations of attachment figures facilitate recovery following upsetting autobiographical memory recall. J. Pers. Soc. Psychol. 103, 362-378. doi: $10.1037 / \mathrm{a} 0028125$

Shaver, P. R., and Mikulincer, M. (2002). Attachment-related psychodynamics. Attach. Hum. Dev. 4, 133-161. doi: 10.1080/14616730210154171

Snodgrass, J. G., and Vanderwart, M. (1980). A standardized set of 260 pictures: norms for name agreement, image agreement, familiarity, and visual complexity. J. Exp. Psychol. 6, 174-215. doi: 10.1037/0278-7393.6.2.174

Sroufe, L. A., and Waters, E. (1977). Attachment as an organizational construct. Child Dev. 48, 1184-1199. doi: 10.2307/1128475

Taylor, S. E., Seeman, T. E., Eisenberger, N. I., Kozanian, T. A., Moore, A. N., and Moons, W. G. (2010). Effects of a supportive or an unsupportive audience on biological and psychological responses to stress. J. Pers. Soc. Psychol. 98, 47-56. doi: $10.1037 / \mathrm{a} 0016563$

Thompson, R. A. (1994). Emotion regulation: a theme in search of definition. Monogr. Soc. Res. Child Dev. 59, 25-52. doi: 10.2307/1166137

Tucker, J. S., and Anders, S. L. (1998). Adult attachment style and nonverbal closeness in dating couples. J. Nonverb. Behav. 22, 109-124. doi: 10.1023/A: 1022980231204

Uchino, B. (2009). Understanding the links between social support and physical health: a lifespan perspective with emphasis on the separability of perceived and received support. Perspect. Psychol. Sci. 4, 236-255. doi: 10.1111/j.1745-6924. 2009.01122.x

Vrij, A. (2004). Why professionals fail to catch liars and how they can improve. Legal Criminol. Psychol. 9, 159-181. doi: 10.1348/1355325041719356

Wallin, D. J. (2007). Attachment in Psychotherapy. New York, NY: Guilford Press.

Weisbuch, M., and Ambady, N. (2008). Non-conscious routes to building culture: nonverbal components of socialization. J. Conscious. Stud. 15, 159-183.

Willander, J., and Larsson, M. (2008). The mind's nose and autobiographical odor memory. Chemosens. Percept. 1, 210-215. doi: 10.1007/s12078-008-9026-0 
Xiao, R., Li, X., Li, L., and Wang, Y. (2016). Can we distinguish emotions from faces? Investigation of implicit and explicit processes of peak facial expressions. Front. Psychol. 7:1330. doi: 10.3389/fpsyg.2016. 01330

Zayas, V., and Shoda, Y. (2005). Do automatic reactions elicited by thoughts of romantic partner, mother, and self relate to adult romantic attachment? Pers. Soc. Psychol. Bull. 31, 1011-1025. doi: 10.1177/01461672042 74100

Zeanah, C. H., and Gleason, M. M. (2010). Reactive Attachment Disorder: A Review for DSM-V. Washington, DC: American Psychiatric Association.
Conflict of Interest Statement: The authors declare that the research was conducted in the absence of any commercial or financial relationships that could be construed as a potential conflict of interest.

Copyright (C) 2019 Sim, Shin and Sohn. This is an open-access article distributed under the terms of the Creative Commons Attribution License (CC BY). The use, distribution or reproduction in other forums is permitted, provided the original author(s) and the copyright owner(s) are credited and that the original publication in this journal is cited, in accordance with accepted academic practice. No use, distribution or reproduction is permitted which does not comply with these terms. 


\section{APPENDIX}

(1) Secure attachment scenario primed by non-verbal cues of significant others

Call to mind a warm moment when you were with someone; recall where you were and what you were doing at that moment and what made you feel so warm. Perhaps the other person was extremely supportive, did not judge you, and accepted you just as you are. More specifically, recollect in detail what the non-verbal cues of the other person were like at that moment, including the facial expression, hand gestures, bodily posture, and voice tone. With this in mind, write at least 3-5 sentences to describe these non-verbal cues and the situation, along with your feelings at the time.

\section{(2) Insecure attachment scenario primed by non-verbal cues of significant others}

Call to mind a cold moment when you were with someone; recall where you were and what you were doing at that moment and as what made you feel discouraged, rejected, or afraid. Perhaps the other person was judgmental and was accepting of you only when you performed at or above a certain level. More specifically, recollect in detail what the non-verbal cues of the other person were like at that moment, including the facial expression, hand gestures, bodily posture, and voice tone. With this in mind, write at least 3-5 sentences to describe these non-verbal cues and the situation, along with your feelings at the time.

\section{(3) Secure and insecure attachment scenarios primed by verbal cues of significant others}

The secure attachment scenario used here is the same as that in (1), but instructions for the non-verbal cue portion were changed to "More specifically, what did the other person tell you at that moment? Recollect the content of his or her words in detail, and write at least 3-5 sentences to describe those words and the situation, along with your feelings at the time." The insecure attachment scenario primed by verbal cues of significant others is the same as the insecure attachment scenario used in (2), but with the non-verbal cues changed to verbal cues, as shown above. 